\title{
Burnout and Secondary Trauma Among Forensic Interviewers of Abused Children
}

\section{Brian E. Perron and Barbara S. Hiltz}

\begin{abstract}
This study examined factors associated with burnout and secondary trauma among forensic interviewers of abused children. Sixty-six forensic interviewers who are affiliated with advocacy centers across the United States completed an online survey. The Oldenburg Burnout Inventory and Secondary Traumatic Stress Scale were used to measure burnout and secondary trauma, respectively. Results indicate that organizational satisfaction has a moderate inverse relationship with burnout and a slight inverse relationship with secondary trauma. The number of forensic interviews conducted or length of employment in forensic interviewing did not have a strong relationship with either burnout or secondary trauma.
\end{abstract}

KEY WORDS: Forensic Interviewing, Burnout, Secondary Trauma.

Forensic interviewing of children is an investigative process designed to help determine whether abuse has occurred and, if so, elicit detail in a court suitable manner. Many interviewers work as a part of a multidisciplinary investigative team, consisting of personnel from law enforcement, social services, medical staff and the judiciary (Davies, Cole, Albertella, Allen, \& Kekevian, 1996). Interest in forensic interviewing of children has grown substantially over the last ten to 15 years (American Prosecutors Research Institute, 2003). This is evidenced by increased empirical research and practice-oriented publications, forensic interviewing training courses, and the development of practice guidelines by the American Professional Society on the Abuse of Children (1995, 1998, 2002). Moreover, there has been a significant rise in the number of child abuse evaluation centers: In 1992, the National Children's Alliance

Address correspondence to Brian E. Perron, George Warren Brown School of Social Work, Washington University, St. Louis, MO, USA; e-mail: bperron@gwbmail.wustl.edu 
had 22 member centers; by 2003 , that number had grown to nearly 500 associate and full member centers (personal communication, D. Hutchison, November 3, 2003).

When conducting a forensic interview with a child, the interviewer must remain impartial and objective, and employ non-coercive and developmentally sensitive methods (Davies et al., 1996). There are a number of publications on issues related to the interviewing process, including topics such as the use of anatomical dolls (Aldridge, 1997; Everson \& Boat, 1994, 1997; Samra \& Yuille, 1996), disclosure (Bradley \& Wood, 1996; Berliner \& Conte, 1995; DeVoe \& Faller, 1999; Goodman-Brown, Edelstein, Goodman, Johnes, \& Gordon, 2003; Sorenson \& Snow, 1991), linguistics (Walker, 1994), and memory and suggestibility (Bruck \& Ceci, 1999; Ceci \& Bruck, 1993; Saywitz, Goodman, Nicholas \& Moan, 1991; Saywitz \& Lyon, 2002).

There have been few empirical attempts to understand the training and support needs of forensic interviewers, or the consequences of doing this type of work. The demands of forensic interviewing, like other human service professions who are intimately engaged in the lives of other people, can be a considerable source of stress. Such stress over time has been found to have a significant association with both burnout (Demerouti, Bakker, Nachreiner, \& Ebbinghaus, 2002; Maslach \& Jackson, 1986) and secondary trauma (Bride, Robinson, Yegidis, \& Figley, 2004; Figley, 1995). Burnout, a condition that is commonly found among human service providers (see Azar, 2000; Maslach \& Jackson, 1986), is a condition that emerges through chronic interpersonal stressors in the workplace, manifesting in feelings of exhaustion, cynicism and detachment from the job, and ineffectiveness (Maslach, Schaufeli, \& Leiter, 2001). It is associated with absenteeism, intentions to leave a job, turnover, low productivity and effectiveness, feelings of depression, anxiety and low self-esteem (Maslach et al., 2001). Secondary trauma, on the other hand, is a cluster of symptoms that is nearly identical to PTSD (Figley, 1999). According to Figley (1999), this condition results from the stress of working or intimately knowing somebody who has been traumatized or is suffering.

At present, no studies have empirically examined these conditions in the context of forensic interviewing of children who have been abused (i.e., sexual, physical, or witness of abuse). As such, it remains unclear how to effectively structure the work environment or the types of supportive services that can minimize the risks or ameliorate 
the consequences of performing this type of work. Therefore, the purpose of this study is to bridge this gap by critically examining the factors associated with burnout and secondary trauma among forensic interviewers of children.

\section{Background}

\section{Burnout}

Freudenberger (1974) is credited with coining the term burnout, which provided the foundation for extensive research on this condition (Savicki \& Cooley, 1982). While there has been a lack of theory guiding the history of research (Maslach \& Jackson, 1986), a substantial body of knowledge has been produced explaining how a multitude of factors are associated with burnout (see Maslach et al., 2001). The following review of the literature on burnout proceeds by roughly dividing the prior research into two groups. The first group offers an explanation of the etiology of burnout as it relates to selfefficacy, whereas the second group focuses on occupational stressors. While personal characteristics and occupational stressors are described separately, it does not imply they are mutually exclusive or unrelated factors. In fact, there is an important body of literature that emphasizes a dynamic interplay between the workplace and emotions. It is beyond the scope of this article to give this area adequate attention. Brief and Weiss (2002) provide an excellent review of the arguments and research.

Self-efficacy. There are a number of theoretical variations that explain burnout based on characteristics of the individual. For example, Demerouti et al. (2002) surmise that burnout arises through an individual's appraisal of stressful situations, which is mitigated by the individual's perceived self-efficacy in coping with the stress (Miller \& Seltzer, 1991). Self-efficacy is the person's belief in his or her ability to organize and carry out an action directed toward a specific goal (Bandura, 1997; Friedman, 2003). Friedman (2003) examined self-efficacy and burnout among teachers and found that self-efficacy in relation to the teachers' beliefs in their ability to influence social and political forces were strong predictors of burnout. Self-efficacy and burnout have also been examined by Cherniss (1995) and Leiter (1991). 
Occupational Stressors. Examining the role of occupational stressors has constituted a significant portion of the burnout research, particularly as it relates to the mental health status of its workers (Cherniss, 1995). The research on job-related stress is extensive, with the journal Work \& Stress being devoted exclusively to this topic (Brief \& Weiss, 2002). In human services research, there is evidence that links stress with high caseloads (Buckhalt, Marchetti, \& Bearden, 1990), levels of role clarity (Blumenthal, Lavender, \& Hewson, 1998), and client characteristics and behaviors (Chung, Corbett, \& Cummella, 1995; Dyer \& Quine, 1998; Mitchell \& Hastings, 2001).

Demerouti et al. (2002) considered burnout as a long-term consequence of mental strain, which can be attributed to inadequate job design. They found evidence that burnout and mental strain can be empirically differentiated using the Oldenburg Burnout Inventory, noting that burnout is a chronic ongoing reaction to prolonged strain whereas mental strain is an immediate reaction to specific work conditions. Cherniss (1995), using a longitudinal study, found that professional autonomy and support are factors that strongly mitigate and facilitate the recovery from burnout.

According to Brief and Weiss (2002), the most significant negative experiences of a job are organizationally related (e.g., administration and supervision) rather then operationally related (dealing with victims and danger). This is supported by the work of George (1995) and George and Brief (1992) who found that enthusiastic leaders could energize their followers, whereas distressed leaders can negatively affect their followers (see also Brief \& Weiss, 2002). There is also significant data suggesting that supervision plays a key role in the management of burnout (Azar, 2000). Webster and Hackett (1999) examined burnout among clinical staff members in community mental health agencies and found that burnout was systematically related to the leadership behavior and quality of supervision provided by their clinical supervisors. These findings provide support for Cherniss' (1995) argument that supervisors are key in managing burnout, as they control instrumental aspects of the work environment that are primary contributors to burnout.

\section{Secondary Trauma}

Secondary trauma, also referred to as vicarious trauma, is a relatively new area of empirical study in comparison to the research on burnout. The early work of Figley (1985) suggested that interpersonal networks 
can serve as powerful influences in the recovery from trauma in addition to causing trauma vicariously among the members of the network. McCann and Pearlman (1989) argued that secondary trauma is different than burnout. They stated that burnout may be the "final common pathway of continual exposure to traumatic material" (p. 134), whereas secondary trauma is an acute response. This conceptual difference was not borne out in the research that showed how organizational factors that are not "traumatic" could lead to burnout (see Maslach et al., 2001). Figley (1995) later sought to align vicarious trauma with the DSM-IV definition of PTSD, emphasizing that the condition can emerge from either direct or indirect expose to a traumatic event. From this perspective, it is expected that secondary traumatic stress symptoms include: Re-experiencing the traumatic event (e.g., dreams, distress), avoiding/numbing (e.g., diminished affect, sense of foreshortened future) and persistent arousal (e.g., difficulty concentrating, hypervigilance for self) (see Figley, 1995).

While the literature base on secondary trauma is growing, much of it is conceptual in nature and does not have a corresponding empirical basis. There are a couple of reasons for this. First, the DSM-IV PTSD criteria are based on a cluster of symptoms that have not been well validated (Bride et al., 2004). This creates complications in both the diagnosing trauma disorders and measuring them. Empirical studies have been conducted on the secondary stress reactions of rescue workers in the September 11 bombing (Creamer, 2002), among providers working with survivors of sexual victimization (Salston \& Figley, 2003), emergency room providers (Warren, Lee, \& Saunders, 2003), and mental health workers (see Collins \& Long, 2003).

A recent development in this area of work is the construction of a psychometrically sound instrument that measures secondary trauma (Bride et al., 2004). With this instrument, the field will have the opportunity to maintain consistency across studies to better understand the factors associated with secondary trauma among providers working with traumatized clients.

\section{Method}

\section{Questions and Hypotheses}

The following research question guided the formulation of hypotheses and design of this study: What factors are associated with burnout 
and secondary trauma among forensic interviewers of children? The following hypotheses were formulated based on the foregoing literature review.

Hypothesis 1. Forensic interviewing involves eliciting experiences of traumatic events, which is regarded as a source of stress. Therefore, it is hypothesized that higher numbers of forensic interviews conducted is associated with higher burnout and secondary trauma.

Hypothesis 2. As both burnout and secondary trauma develop over time, it is hypothesized that the length of employment as a forensic interviewer is positively associated with these conditions.

Hypothesis 3. It is hypothesized that perceived self-efficacy in coping with chronic stress moderates the relationship between occupational stress and both burnout and secondary trauma. Thus, higher self-efficacy will be associated with lower burnout and secondary trauma.

Hypothesis 4. Like self-efficacy, it is hypothesized that organizational satisfaction moderates the relationship between occupational stress and both burnout and secondary trauma. Thus, higher organizational satisfaction will be associated with lower burnout and secondary trauma.

While these hypotheses suggest that the same factors are associated with both burnout and secondary trauma, it is not implied that they are the same construct. As these conditions differ conceptually, it is expected that there will be differences in the overall variances of each condition accounted for by each factor. However, the empirical basis for secondary trauma is not fully developed to inform such specifications in the hypotheses.

\section{Sampling and Design Strategy}

This study invoked a multi-stage sampling strategy to develop a list of potential participants. This was done by taking contact information of child abuse evaluation centers listed on the National Children's Alliance (NCA) website ${ }^{1}$. These organizations $(N=301)$ were contacted by e-mail and provided an overview of the research project's purpose. Contact information for forensic interviewers that 
they employed or who were affiliated with their organization was requested. Seventy-six messages were returned because the e-mail addresses were invalid, and 12 centers replied indicating that they do not presently conduct forensic interviews. In sum, 75 centers provided contact information for 125 interviewers.

Data were collected using a cross-sectional survey design. The forensic interviewers on the mailing list were sent a recruitment message by e-mail requesting their participation in the study. The e-mail message contained a link that directed them to an online survey if they agreed to participate. No financial incentives were offered. Prior to completing the survey, participants were provided additional information about the study and acknowledged their informed consent by selecting a link to bring them to the survey. After the online survey was completed, the data were stored in a secure database by the company hosting the survey. The data were then downloaded and analyzed. The online survey was comprised of a demographics questionnaire and standardized scales that are described in the next section.

It is also noted that the online survey was anonymous and did not present any risks to the participants. No information was requested that could identify either the participants or their respective agencies. The Institutional Review Board of the affiliated university also approved this study.

\section{Instruments}

Oldenburg Burnout Inventory (OLBI). The OLBI was selected to measure the burnout. This is a 15-item instrument that asks respondent to rate how they feel about statement using a four-point Likert scale, 1 ("strongly agree") to 4 ("strongly disagree"). The OLBI is comprised of two subscales, exhaustion and disengagement. The exhaustion subscale has seven items; disengagement, eight. After reverse scoring eight of the total items, averages calculated for each subscale with higher scores indicating higher burnout. In prior studies, the OLBI exhibited good test-retest reliability and internal reliability $(\alpha>$.80) for both subscales (Demerouti et al., 2002, 2003).

The original version of the OLBI was developed in German. This study presents its first use in English. For this study, the author of the OLBI provided a translated version of the original instrument. Then, an independent reviewer checked the translation to ensure item consistency. While the English version of the OLBI has not 
been validated among an English speaking population, a prior study shows good convergent validity with a translated version of the widely used Maslach Burnout Inventory-General Survey (MBI-GS) (see Maslach, Jackson, \& Leiter, 1997). Specifically, the OLBI and MBI-GS were administered to a Greek population and evidenced good convergent validity (Demerouti et al., 2003). An assumption of this study is that the OLBI maintains the same properties in relation to the MBI-GS when it is administered in English.

Secondary Traumatic Stress Scale (STSS). The STSS is a 17-item scale designed to measure secondary trauma on three dimensions: Intrusion, avoidance, and arousal (Bride et al., 2004). These scores can also be summed to produce a total score, which is the strategy employed in this study. On a five-point Likert scale, respondents indicate their agreement with items that reflect specific responses to their work with trauma victims. A higher total score indicates higher secondary trauma. This instrument demonstrates good construct validity and internal reliability $(\alpha=.93)$ (Bride et al., 2004).

Satisfaction with Organization Scale (SOS). The SOS was developed by Kimball, Shumway, Korinek, and Arredondo (2002b), patterned after the Satisfaction with Life Scale (Diener, Emmons, Larsen, \& Griffin, 1985). It is a five-item instrument utilizing a sixpoint Likert scale. It measures employees' perceptions of satisfaction with their work organization (see also Kimball, Shumway, Korinek, \& Arredondo, 2002c). All the items are summed to produce a total satisfaction score. The total scores range from 5 to 30, with the higher scores reflecting higher satisfaction. The SOS has good psychometric properties, evidenced by its internal consistency $(\alpha=.87)$ and test-retest reliability $(r=.82)$.

The General Self-Efficacy Scale (GSE). The GSE measures general self-efficacy, with a focus on coping with hassles and stressful events (Schwarzer \& Jerusalem, 1995). It is a ten-item instrument that utilizes a 4-point response scale, ranging from 1 to 4 . A composite self-efficacy score is obtained by summing all the items. A higher score represents more self-efficacy. For internal reliability, the majority of analyses have reported a Cronbach's alpha that exceeds .80 (see also Schwarzer \& Jerusalem, 1995; Schwarzer \& Born, 1997; Schwarzer, Mueller, \& Greenglass, 1999). 
Demographics Questionnaire. This questionnaire was developed to gather information about the respondents' age, gender, race, level of education, percent of job associated with forensic interviewing, average number of interviews conducted a month, and length of employment in current position.

\section{Data Analysis Plan}

$T$-test and Pearson product moment correlations were selected to test the hypotheses. As this pilot study utilized a small sample, the maximum allowable risk for a Type I error was set at .10. The normality of variables was also examined to ensure that the assumptions of the parametric tests were met. The SAS System (version 8) was used to aid in all the statistical analyses.

\section{Results}

Recruitment messages were sent via e-mail to 125 potential subjects. Ten messages were returned non-deliverable. Of the 115 successfully delivered messages, sixty-six subjects completed the survey, which produced an overall response rate of $60 \%$. To ensure that all respondents were substantively engaged in forensic interviewing, those who indicated that less than $25 \%$ of their job related to forensic interviewing $(n=6)$ were excluded from the sample. Of those remaining, fourteen indicated that $25-50 \%$ of their job related to forensic interviewing, 18 indicated $50-75 \%$, and 28 indicated $75-100 \%$; thus, the sample size on which the following analyses were performed was 60 .

Age was measured as a categorical variable in five-year increments. It was normally distributed, ranging from less than less than 20 years of age to over 55. The majority of respondents were $30-34$ years of age $(26.7 \%)$. Ninety percent of the sample was female $(n=54)$. There was a high number of Caucasians $(n=52)$ in comparison to those who are Hispanic or Latino $(n=3)$, American Indian/ Alaskan Native $(n=4)$, and Black $(n=1)$. Twenty-five respondents reported having a Bachelor's degree, 33 a Master's degree, and two a professional degree (i.e., law or doctorate). Most reported working in urban areas $(n=32)$, followed by suburban $(n=17)$ and rural areas $(n=11)$. None of the respondents reported receiving counseling or therapy, but 24 respondents indicated receiving clinical supervision on a regular basis. All respondents stated that the majority of the forensic interviews they conduct are sexual abuse cases. 
Descriptive statistics and reliability estimates for each instrument are reported in Table 1. Reliability estimates for all the scales were comparable to estimates computed in prior studies. The reliability estimate for the disengagement subscale was slightly lower than prior studies, although it was at an acceptable level in comparison to Nunally's minimally acceptable level of .70 (as cited in Hatcher \& Stepanski, 1994). While all the subscales were significantly correlated, they were not highly intercorrelated $(r<.64)$ to suggest that they are the same constructs.

\section{Tests of Hypotheses}

Hypothesis 1. A correlation coeffecient was computed to measure the association between the number of forensic interviews conducted each month and the dependent measures (i.e., burnout and secondary trauma). As the reported number of interviews was skewed, a log transformation was conducted prior to computations. The correlation coefficients indicate that the number of interviews is not significantly related to disengagement $(r(56)=.07, \mathrm{~ns})$, exhaustion $(r(56)=.10, \mathrm{~ns})$ or secondary trauma $(r(55)=-.11, \mathrm{~ns})$.

A $t$-test (two-tailed) was then used to examine the difference in mean burnout and secondary trauma scores by percentage of work directly related to forensic interviewing (i.e., 25-75\% versus $75-100 \%)$. Subjects who stated that $75-100 \%$ of their work is directly related to forensic interviewing scored slightly higher on the disengagement score $(t(57)=1.98, p=.053)$, but there were no differences on the exhaustion $(t(43.4)=1.62$, ns) or secondary trauma $(t(56)=.57, \mathrm{~ns})$ scores. Thus, only modest support was present to suggest that a high proportion of work directly related to forensic interviewing is associated with disengagement.

Hypothesis 2. A correlation coefficient was computed to measure the association between time in current position and the dependent measures. Prior to computations, a skewness on the time variable was resolved by a log transformation. In the analysis, a significant association between years of employment and burnout on the disengagement subscale $(r(57)=.27, p<.05)$ was found. However, years of employment was not correlated with exhaustion $(r(57)=.16, \mathrm{~ns})$ or secondary trauma $(r(56)=.18, \mathrm{~ns})$. 


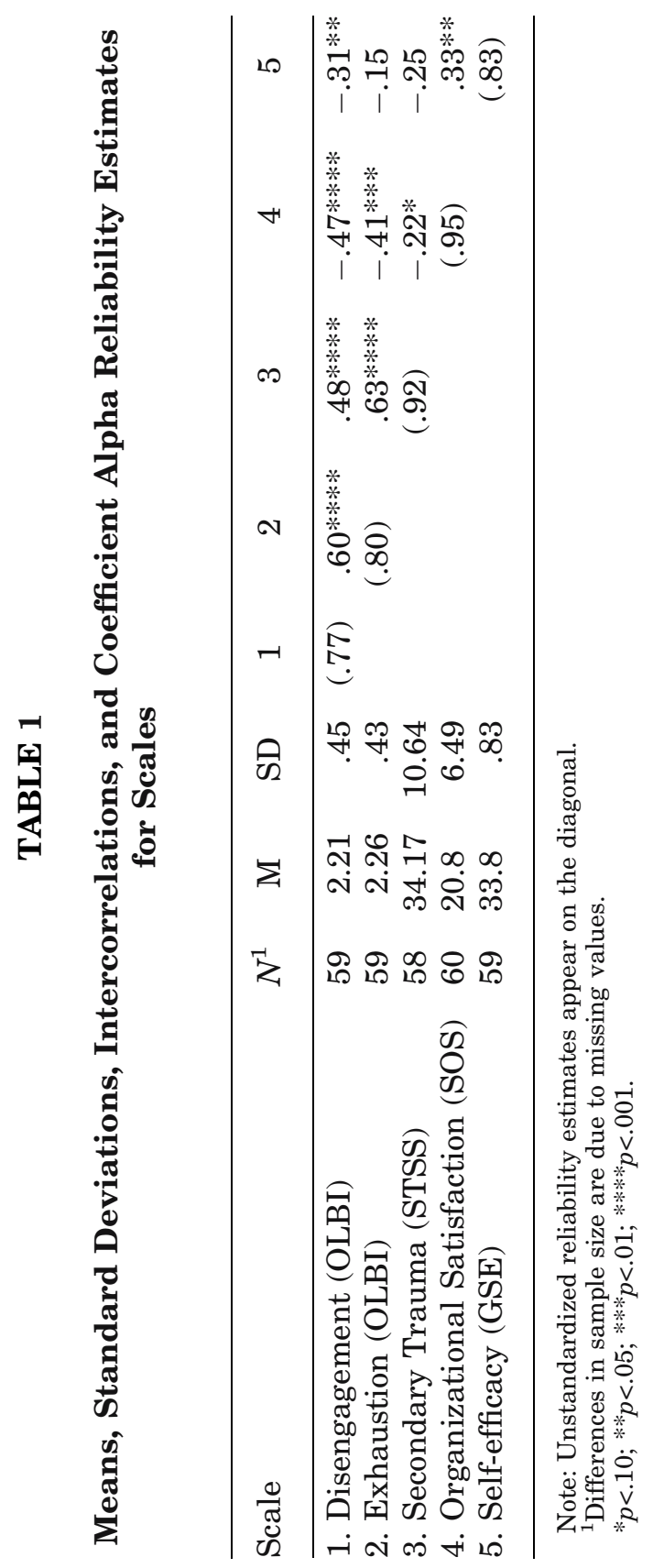


Prior researchers have indicated that burnout develops over time in stressful work conditions, usually after a period of two years (e.g., Cherniss, 1980; Demerouti, Bakker, Nachreiner, \& Ebbinghaus, 2002). Thus, mean group scores of individuals who were employed for two years or less in their current position were compared with those employed for more than 2 years. Table 2 summarizes these descriptive statistics. A $t$-test analysis (two-tailed) was computed to identify significant differences between the two groups. Those with more than two years of employment had significantly higher disen-

TABLE 2

\section{Associations Between OLBI subscales, STSS and Forensic Interviewer Characteristics}

\begin{tabular}{|c|c|c|c|c|c|c|c|}
\hline \multirow[b]{3}{*}{ Variable } & \multirow[b]{3}{*}{$N$} & \multicolumn{4}{|c|}{ OLBI } & \multirow{2}{*}{\multicolumn{2}{|c|}{$\begin{array}{c}\text { STSS } \\
\begin{array}{c}\text { Secondary } \\
\text { Trauma }\end{array}\end{array}$}} \\
\hline & & \multicolumn{2}{|c|}{$\begin{array}{c}\text { Disengage- } \\
\text { ment }\end{array}$} & \multicolumn{2}{|c|}{ Exhaustion } & & \\
\hline & & M & $\mathrm{SD}$ & M & SD & M & SD \\
\hline \multicolumn{8}{|c|}{ Number of interviews } \\
\hline$\leq 20$ & 38 & 2.19 & .50 & 2.24 & .45 & 34.56 & 11.80 \\
\hline$>20$ & 22 & 2.21 & .38 & 2.29 & .39 & 33.55 & 8.63 \\
\hline \multicolumn{8}{|c|}{ Percentage of job related to forensic interviewing } \\
\hline $25-75 \%$ & 32 & $2.09 *$ & .42 & 2.17 & .33 & 29.90 & 12.60 \\
\hline $75-100 \%$ & 28 & 2.31 & .47 & 2.36 & .51 & 30.36 & 16.28 \\
\hline \multicolumn{8}{|c|}{ Length in current position } \\
\hline$\leq 2$ years & 36 & 2.14 & .48 & 2.21 & .46 & 33.11 & 11.27 \\
\hline$>2$ years & 24 & 2.88 & .41 & 2.34 & .38 & 35.91 & 9.52 \\
\hline \multicolumn{8}{|c|}{ Self-efficacy } \\
\hline Low & 32 & 2.26 & .43 & 2.29 & .34 & 35.42 & 13.48 \\
\hline High & 28 & 2.12 & .48 & 2.22 & .52 & 32.74 & 15.43 \\
\hline \multicolumn{8}{|c|}{ Organizational Satisfaction } \\
\hline Low & 30 & $2.35^{* *}$ & .43 & $2.38^{*}$ & .46 & 35.58 & 12.42 \\
\hline High & 30 & 2.03 & .43 & 2.14 & .37 & 32.76 & 8.48 \\
\hline
\end{tabular}

Note: Independent sample $t$-tests were used to test mean differences. $* p<.05 ; * * p<.01$. 
gagement scores $(t(57)=2.78, p=.007)$ than subjects with two years or less. There were no significant differences between the mean scores on the exhaustion $(t(31.4)=1.04, \mathrm{~ns})^{2}$ or secondary trauma scales $(t(56)=1.22, \mathrm{~ns})$.

Based on these analyses, there is only modest support indicating that duration of employment in forensic interviewing is significantly related to disengagement.

Hypothesis 3. A correlation coefficient was computed to examine the relationship between self-efficacy and the dependent measures. As indicated in Table 1, self-efficacy was significantly related to disengagement $(r(56)=-.31, p<.05)$ and secondary trauma $(r(55)=-.25, \quad p<.1$, but not exhaustion $r(56)=-.15$, ns. A median split was then conducted on the selfefficacy scores to create two groups of subjects with low and high self-efficacy. The mean burnout and secondary trauma scores of these two groups were then compared using a $t$-test analysis. There were no significant differences in the mean scores on any of the three dependent measures (see Table 2). Thus, there is only little support that disengagement and secondary trauma are associated with self-efficacy.

Hypothesis 4. Correlation analyses indicated that organizational satisfaction is associated with all the dependent measures (see Table 1): Disengagement $(r(57)=-.47, p=.0002)$, exhaustion $(r(57)=-.41, p=.0013)$ and secondary trauma $(r(56)=-.22, p=.095)$. A median split was then conducted on the organizational satisfaction scores to create groups of subjects reporting either low or high organizational satisfaction. The mean burnout and secondary trauma scores of these two groups were compared using a $t$-test analysis (two-tailed). The group with higher organizational satisfaction had significantly lower scores on both the disengagement $(t(57)=2.87, p=.006)$ and exhaustion $(t(57)=2.18, p=.033)$ scales (see Table 2$)$. However, there were no significant differences in secondary trauma scores $(t(49.5)=1.01, \mathrm{~ns})^{2}$.

Overall, there was modest support for the second hypothesis that duration of employment as a forensic interviewer is positively associated with one aspect of burnout - that is, disengagement. There was also modest support for the third hypothesis that self-efficacy is 
negatively associated with disengagement and secondary trauma. There was stronger evidence for the fourth hypothesis that organizational satisfaction is negatively associated with both aspects of burnout and secondary trauma. While these data do not indicate causal relationships, they do follow prior studies that organizational factors play a key role in the development of burnout (see Maslach, Schaufeli, \& Leiter, 2001).

\section{Discussion}

This Internet-based study examined how various personal and organizational factors are associated with burnout and secondary trauma. The sample was a homogenous group, comprised primarily of college-educated, Caucasian females who are employed as forensic interviewers at child abuse evaluation centers associated with the NCA. Generalizing these findings to other populations where forensic interviewing may constitute only a small part of overall job duties is not recommended.

The strongest relationship identified in this study was between organization satisfaction and burnout (i.e., disengagement and exhaustion). Organization satisfaction also had a small but statistically significant relationship with secondary trauma. There was also some evidence to suggest that self-efficacy is inversely associated with both disengagement and secondary trauma. Based on the conceptual framework, it can be suggested that self-efficacy moderates the relationship between occupational stress and the development of various mental health symptoms. There was no substantive evidence that personal characteristics or the duties associated with forensic interviewing had a significant relationship with either burnout or secondary trauma to support the other hypotheses.

There are a couple reasons to explain the occurrence of these nonsignificant findings. According to Figley (1999), secondary trauma arises from "knowledge about an event experienced by a significant other" (p. 10). The majority of the participants in this study are employed at child abuse evaluation centers, which means that the interviews are conducted at the center. Thus, the manner in which the forensic interviewing services are offered is not conducive to the development of strong relationships with the victimized children. The process of forensic interviewing is often structured or semi-structured, objective, and time-limited, which may reduce the emotional connectedness between the interviewers and children. 
Additionally, while the content of the stories and the response of the victimized children may present as a considerable source of stress, organizational factors may serve to increase or buffer the impact of this stress over time. This is suggested by prior findings about burnout and organizational influences (see Maslach et al., 2001). In this study, there was a small but statistically significant inverse relationship with secondary trauma, which suggests that other more specific organizational factors may for account the overall variance in secondary trauma.

Research can move in a number of directions to more fully develop an empirical picture of the mental health consequences of forensic interviewing. One direction is to focus on the organizational context of forensic interviewing. The inclusion of organizational influences in the development of burnout has made a significant contribution to this highly developed area of research. However, the present research on secondary trauma focuses almost exclusively on the relationship between the victim and service provider, largely ignoring the organizational factors that may meaningfully impact the relationship. For example, it may be useful to explore questions such as: Does collegial support reduce secondary trauma among service providers who work traumatized clients? Or, can clinical supervision effectively reduce secondary trauma among service providers?

Supervisors who are concerned about burnout among forensic interviewers may want to give attention to aspects of the organization and organizational climate that may be a source of stress. For example, Reid et al. (1999a, b) found that specific coping strategies such as informal contacts with colleagues promoted job satisfaction, in turn lowering burnout. This buttressed the prior work that describes a meaningful association between collegial support and burnout (Corrigan, Holmes, \& Luchins, 1995). However, as no interventions have yet shown to be effective in reducing burnout and secondary trauma, suggestions to this end cannot be offered.

It is important that these findings and implications for research and practice are carefully considered in light of the limitations of the study. While the overall response rate was at an acceptable level $(60 \%)$ the sample size was low $(N=60)$, which elevated the risk of a Type II error. In addition to reducing this error, an increased sample size would also allow for the use of multivariate analyses to more fully explore the various relationships between the independent and dependent variables. 
Another limitation reflects the instruments selected for this study. While all of them have strong psychometric properties, the OLBI, STSS, and SOS are relatively new; therefore, it is unclear as to what extent measurement error has crept into the study. Also this study did not utilize a sample size large enough to allow for a confirmatory factor analysis to be employed on the translated version of the OLBI to determine if the two-factor structure was maintained in the translation. These instruments were also administered via the Internet, whereas prior reliability and validity studies used the original paperpencil format. Thus, it remains unclear as to whether the difference in administration of these instruments contained measurement error.

Despite the limitations, this study has made an empirical contribution in helping understand the factors associated with burnout and secondary trauma among the specialized field of forensic interviewing. This study has also helped lay a foundation for future research efforts both further exploration of relationships and development of instruments for measuring these mental health conditions.

\section{Notes}

1. www.nca-online.org

2. $t$-test with Satterthwaite correction for degrees of freedom (df) due to inequality of variances.

\section{References}

Aldridge, N. C. (1997). Strengths and limitations of forensic child sexual abuse interviews with anatomical dolls: An empirical review. Journal of Psychopathology and Behavioral Assessment, 20(1), 1-41.

American Prosecutors Research Institute (2003). Finding words: Half a nation by 2010. Alexandria: Author.

American Professional Society on the Abuse of Children (1995). Practice guidelines - use of anatomical dolls in child sexual abuse assessments. Chicago: Author.

American Professional Society on the Abuse of Children (1998). Practice guidelines psychosocial evaluation of suspected sexual abuse in young children (2nd ed.). Chicago: Author.

American Professional Society on the Abuse of Children (2002). Practice guidelines Investigative interviewing in cases of alleged child abuse. Chicago: Author.

American Psychiatric Association (1994). Diagnostic and statistical manual of mental disorders (3rd ed., rev.). Washington, D. C.: Author.

Azar, S. T. (2000). Preventing burnout in professionals and paraprofessionals who work with child abuse and neglect cases: A cognitive behavioral approach to supervision. JCLP/In Session: Psychotherapy in Practice, 56(5), 643-663. 
Bandura, A. (1997). Self-efficacy: The exercise of control. New York: H. Freeman.

Berliner, L., \& Conte, J. R. (1995). The effects of disclosure and intervention on sexually abused children. Child Abuse \& Neglect, 19(3), 371-384.

Bradley, A. R., \& Wood, J. M. (1996). How do children tell? The disclosure process in child sexual abuse. Child Abuse \& Neglect, 20(9), 881-891.

Bride, B. E., Robinson, M. R., Yegidis, B., \& Figley, C. R. (2004). Development and validation of the Secondary Traumatic Stress Scale. Research on Social Work Practice, 14(1), 27-35.

Brief, A. P., \& Weiss, H. M. (2002). Organizational behavior: Affect in the workplace. Annual Review in Psychology, 53, 279-307.

Bruck, M., \& Ceci, S. J. (1999). The suggestibility of children's memory. Annual Review in Psychology, 50, 419-439.

Buckhalt, J. A., Marchetti, A., \& Bearden, L. J. (1990). Sources of job stress and job satisfaction reported by direct-care staff of large residential mental retardation facilities. Education and Training in Mental Retardation, 25, 344-351.

Ceci, S., \& Bruck, M. (1993). Suggestibility of the child witness: A historical review and synthesis. Psychological Bulletin, 7(2), 403-439.

Cherniss, C. (1980). Professional burnout in human service organizations. New York: Praeger.

Cherniss, C. (1995). Beyond burnout. New York: Routledge.

Chung, M. C., Corbett, J., \& Cumella, S. (1995). Relating staff burnout to clients' challenging behavior in people with a learning difficulty: Pilot study 2. European Journal of Psychiatry, 10, 155-165.

Collins, S., \& Long, A. (2003). Working with the psychological effects of trauma: consequences for mental health-care workers: A literature review. Journal of Psychiatric and Mental Health Nursing, 10(4), 417-424.

Corrigan, P. W., Holmes, E. P., \& Luchins, D. (1995). Burnout and collegial support in state psychiatric hospital staff. Journal of Clinical Psychology, 51(5), 703-710.

Davies, D., Cole, J., Albertella, L., Allen, K., \& Kekevian, H. (1996). A model for conducting forensic interviews with child victims of abuse. Child Maltreatment, 1(3), 189-199.

Demerouti, E., Bakker, A. B., Nachreiner, F., \& Ebbinghaus, M. (2002). From mental strain to burnout. European Journal of Work and Organizational Psychology, 11(4), $423-441$.

Demerouti, E., Bakker, A. B., Vardakou, I., \& Kantas, A. (2003). The convergent validity of two burnout instruments: A multitrait-multimethod analysis. European Journal of Psychological Assessment, 19, 12-23.

DeVoe, E. R., \& Faller, K. C. (1999). The characteristics of disclosure among children who may have been sexually abused. Child Maltreatment, 4(3), 217-227.

Diener, E., Emmons, E., Larsen, R. A., \& Griffin, S. (1985). The satisfaction with life scale. Journal of Personality Assessment, 49, 71-75.

Dyer, S., \& Quine, L. (1998). Predictors of job satisfaction and burnout among the directcare staff of a community learning disability service. Journal of Applied Research in Intellectual Disabilities, 11, 320-332.

Everson, M. D., \& Boat, B. (1994). Putting the anatomical doll controversy in perspective: An examination of the major doll uses and related criticisms. Child Abuse \& Neglect, $18(2), 113-130$.

Everson, M. D., \& Boat, B. W. (1997). Anatomical dolls in child sexual abuse assessments: A call for forensically relevant research. Applied Cognitive Psychology, 11, S55-S74.

Figley, C. R., (Ed.). (1995). Compassion fatigue: Coping with secondary traumatic stress disorder in those who treat the traumatized. New York: Brunner/Mazel.

Figley, C. R. (1999). Compassion fatigue: Toward a new understanding of the costs of caring. In B. H. Stamm (Ed.), Secondary traumatic stress: Self-care issues for 
clinicians, researchers, \& educators (2nd ed., pp. 3-28). Lutherville, MD: Sidran Press.

Figley, C. R. (1985). The role of the family: both haven and headache. In M. Lystad (Ed.), Role stressors and supports for emergency workers (pp. 84-94). Washignton, D. C: U.S. Government Printing OfficeDHHS Publication No. ADM 85-1408.

Freudenberger, J. J. (1974). Staff burn-out. Journal of Social Issues, 30, 159-165.

Friedman, I. A. (2000). Burnout in teachers: Shattered dreams of impeccable professional performance. Journal of Clinical Psychology, 56(5), 595-606.

Friedman, I. A. (2003). Self-efficacy and burnout in teaching: The importance of interpersonal-relations efficacy. Social Psychology of Education, 6, 191-215.

George, J. M. (1995). Leader positive mood and group performance: The case of customer service. Journal of Applied Social Psychology, 25(9), 778-794.

George, J. M., \& Brief, A. P. (1992). Feeling good - doing good: A conceptual analysis of the mood at work and organizational spontaneity relationship. Psychological Bulletin, 112(2), 310-329.

Goodman-Brown, T. B., Edelstein, R. S., Goodman, G. S., Jones, D. P. H., \& Gordon, D. S. (2003). Why children tell: A model of children's disclosure of sexual abuse. Child Abuse \& Neglect, 27, 525-538.

Hatcher, L., \& Stepanski, E. J. (1994). A step-by-step approach to using SAS System for univariate and multivariate statistics. Cary: SAS Institute.

Kimball, T. G., Shumway, S. T., Korinek, A., \& Arredondo, R. (2002a). Using the Satisfaction with Organization Scale (SOS): Two samples compared. Employee Assistance Quarterly, 18(1), 47-55.

Kimball, T. G., Shumway, S. T., Korinek, A., \& Arredondo, R. (2002b). Satisfaction with Organization Scale (SOS): Reliability and validity of a revised instrument. Employee Assistance Quarterly, 17(4), 45-52.

Kimball, T. G., Shumway, S. T., Korinek, A., \& Arredondo, R. (2002c). Using the Satisfaction with Organization Scale (SOS): Two samples compared. Employee Assistance Quarterly, 18(1), 47-55.

Leiter, M. (1991). The dream denied: Professional burnout and the constraints of human service organizations. Canadian Psychology, 32(4), 547-555.

Maslach, C., \& Jackson, S. E. (1986). Maslach Burnout Inventory Manual (2nd ed.). Palo Alto: Consulting Psychologists Press.

Maslach, C., Jackson, S. E., \& Leiter, M. P. (1997). Maslach Burnout Inventory Manual (3rd ed.). Palo Alto: Consulting Psychologists Press.

Maslach, C., Schaufeli, W. B., \& Leiter, M. P. (2001). Job burnout. Annual Review in Psychology, 52, 397-442.

McCann, L., \& Pearlman, L. A. (1989). Vicarious traumatization: A framework for understanding the psychological effects of working with victims. Journal of Tramatic Stress, 3(1), 131-149.

Miller, L. W., \& Seltzer, J. (1991). The relationship between self-efficacy and burnout. Journal of Health and Human Resources Administration, 13(1), 483-488.

Mitchell, G., \& Hastings, R. P. (2001). Coping, burnout, and emotion in staff working in community services for people with challenging behaviors. American Journal on Mental Retardation, 106(5), 448-459.

Reid, Y., Johnson, S., Morant Kuipers, M. E., Szmukler, G., Thornicroft, G., Bebbington, P., \& Prosser, D. (1999a). Explanations for stress and satisfaction in mental health professionals: A qualitative study. Social Psychiatry and Psychiatric Epidemiology, 34, 301-308.

Reid, Y., Johnson, S., Morant Kuipers, M. E., Szmukler, G., Bebbington, P., Thornicroft, G., \& Prosser, D. (1999b). Improving support for mental health staff: A qualitative study. Social Psychiatry and Psychiatric Epidemiology, 34, 309-315.

Sabin-Farrell, R. T. G. (2003). Vicarious traumatization: Implications for the mental health or health workers? Clinical Psychology Review, 23, 449-480. 
Salston, M., \& Figley, C. R. (2003). Secondary traumatic stress effects of working with survivors of criminal victimization. Journal of Trauma Stress, 16(2), 167-174.

Samra, J., \& Yuille, J. C. (1996). Anatomically-neutral dolls: Their effects on the memory and suggestibility of 4- to 6-year-old eyewitnesses. Child Abuse \& Neglect, 20(12), $1261-1272$.

Savicki, V., \& Cooley, E. J. (1982). Implications of burnout research and theory for counselor educators. The Personnel and Guidance Journal, 3, 415-419.

Saywitz, K. J., Goodman, G. S., Nicholas, E., \& Moan, S. F. (1991). Children's memories of a physical examination involving genital touch: Implications for reports of child sexual abuse. Consulting \& Clinical Psychology, 59(5), 682-691.

Saywitz, K. J., \& Lyon, T. D. (2002). Coming to grips with children's suggestibility. In M.Eisen, G.Goodman \& J.Quas (Eds.), Memory and suggestibility in the forensic interview (pp. 85-113). Hillsdale, NH: Erlbaum.

Schwarzer, R. \& Jerusalem, M., (1995). Generalized self-efficacy scale. In J. Weinman, S. Wright, \& M. Johnston, Measures in health psychology: A user's portfolio. Causal and control beliefs (pp. 35-37). Windsor, UK: NFER-Nelson.

Schwarzer, R., \& Born, A. (1997). Optimistic self-beliefs: Assessment of general perceived self-efficacy in thirteen cultures. World Psychology, 3(1-2), 177-190.

Schwarzer, R., Mueller, J., \& Greenglass, E. (1999). Assessment of perceived general self-efficacy on the Internet: Data collection in cyberspace. Anxiety, Stress, and Coping, 12, 145-161.

Shelby, R. A., Stoddart, R. M., \& Taylor, K. L. (2001). Factors contributing to levels of burnout among sex offender treatment providers. Journal of Interpersonal Violence, 16(11), 1205-1217.

Sorenson, T., \& Snow, B. (1991). How children tell: The process of disclosure in child sexual abuse. Child Welfare, 70(1), 3-15.

Walker, A. (1994). Handbook on questioning children: A linguistic perspective. Washington, DC: American Bar Association Center on Children and the Law.

Warren, T., Lee, S., \& Saunders, S. (2003). Factors influencing experienced distress and attitude toward trauma by emergency medicine practitioners. Journal of Clinical Psychology in Medical Settings, 10(4), 293-296. 